This paper is part of the Proceedings of the $3^{\text {rd }}$ International Conference on Design,

\title{
Influence of chlorinated water on mechanical properties of polyethylene and polyvinyl chloride pipes
}

\author{
B. Kowalska ${ }^{1}$, T. Klepka ${ }^{2}$ \& D. Kowalski ${ }^{1}$ \\ ${ }^{1}$ Department of Water Supply and Sewage Disposal, \\ Lublin University of Technology, Poland \\ ${ }^{2}$ Department of Polymer Processing, \\ Lublin University of Technology, Poland
}

\begin{abstract}
Water chlorination is one of the most popular ways of disinfection used in potable water distribution systems. Nevertheless, chlorinated water does influence mechanical properties, structure and characteristics of the surface of plastic water pipes forming the system. This paper presents tests of HDPE and PVC water pipes in different ageing solutions of specific chlorine concentration, $\mathrm{pH}$ and $\mathrm{CaCO}_{3}$ content and in different temperatures. Strength, structure and the chemical stability of samples were determined following different immersion periods in ageing solutions. Static tensile strength tests have not indicated any significant changes in the selected mechanical properties of either HDPE or PVC pipes samples. Infrared spectrometry tests of the chemical structure, however, showed changes in the tested samples indicating material degradation caused by chlorinated water. Keywords: PE pipes, PVC pipes, chlorinated water, degradation, mechanical strength.
\end{abstract}

\section{Introduction}

Plastics, polyethylene and polyvinyl chloride in particular, are commonly used in water distribution systems. In order to assure the required quality and avoid secondary microbiological contamination, the water is disinfected with various disinfectants. Chlorination is one of the most popular ways of water disinfection and is commonly used in water treatment plants. Nonetheless, chlorine compounds 
have strong oxidizing properties, and chlorinated water influences the mechanical properties, structure and characteristics of the surface of plastic water pipes. The mechanical properties of pipes are, moreover, influenced by pressure, temperature and the $\mathrm{pH}$ of the water in contact with the material. Free available chlorine, of widespread use in disinfection, is a sum of aqueous $\mathrm{HOCl}, \mathrm{OCl}^{-}$and $\mathrm{Cl}_{2}$. $\mathrm{HOCl}$ dissociates into $\mathrm{OCl}^{-}$and $\mathrm{H}^{+} . \mathrm{H}^{+}$ion concentration determines the form of free available chlorine in water. Together with the increase of $\mathrm{H}^{+}$ions, the amount of undissociated $\mathrm{HOCl}$ rises, which is more reactive in oxidation of reduced substances than $\mathrm{OCl}^{-}$ion, thus its consumption rises [1]. With $\mathrm{pH}$ ranging between 6.5 and $7.5, \mathrm{HOCl}$ compounds dominate in water, and the maximum rate of material degradation is observed at a pH lower than $7.5[2,3]$. The recommended $\mathrm{pH}$ of water in Poland is between 6.5 and 9.5 [4]. It is believed that polyethylene, among all plastics used for water pipes production, which is the most susceptible to degradation. Hence, information on the interaction between chlorine compounds and polyethylene pipes have been appearing in literature. Nevertheless, no sufficient research data has described the reaction of this disinfectant with polyvinyl chloride; another material used in water pipe production.

Polyethylene degradation usually follows the depletion of antioxidants and stabilizers used in material production processes, which consequently allows chlorine to penetrate into the material [5-10]. Standard stabilizers, a mixture of phenols and phosphates, are rapidly consumed in the reaction with chlorine compounds. Dear and Mason [11] observed degradation of inner walls of polyethylene pipes caused by chlorine, manifesting itself in lowered molecular weight of the material and small axial cracks on the inside pipe wall. Based on research conducted with changeable pressure, temperature, free available chlorine concentration and $\mathrm{pH}$, Hassinen et al. [12] observed that chlorinated water causes substantial reduction in antioxidant levels, and thus pipe degradation. Hassinen et $a l$. [12] and Andersson and Ifwarson [13] arrived at similar conclusions during HDPE pipes tests. Whelton and Dietrich [14] proved that PE pipes ageing under the influence of chlorinated water lead to a reduction in antioxidant levels, increased crystalline content which decreases the amount of amorphous region, chain scission, molecule layering, broadening of the molecular weight distribution, increased hydroxyl, carbonyl, and/or vinyl group content, and visible striations and cracking on the surface. Castagnetti et al. [15] conducted tests on mechanical properties of polyethylene pipes (static tensile test) and chemical (oxidation induction time OIT) with the use of non-chlorinated water and water chlorinated with sodium hypochlorite and chlorine dioxide. The tests were conducted on standardized dumbbell specimens and pipe fragments immersed in ageing solutions. In the case of specimens immersed in the ageing solution, a clear decrease of elongation at rupture and antioxidant content in the material were noted. In addition, chlorine dioxide proved to be much more aggressive than sodium hypochlorite. For pipe fragment samples, no substantial mechanical or chemical changes were observed during the tests. Degradation of PE pipes exposed to chlorine dioxide was presented in publications [13-17]. Tests were conducted in various ageing solutions and temperatures. Antioxidant depletion in 
pipes filled with chlorine dioxide was observed as the disinfectant is greater compared with the chlorine gas [18]. Oertli and Ifwarson [19] proved that polyethylene pipes exposed to non-chlorinated water show a durability 10-30 times longer than pipes filled with chlorinated water. Devilliers et al. [20] tested chlorine influence on oxidation of polyethylene samples exposed to chlorine solutions at various concentrations $(70,400$ and $4000 \mathrm{mg} / \mathrm{L})$ proving that the higher the chlorine concentration the faster the rate of oxidation (chain scission). Gill et al. [21] proved that cross-linked polyethylene (PEX) is also degraded by chlorinated water, which results in mechanical properties and pipe durability deterioration. Field work observations evidenced that brittle fractures in pipes occur particularly in small-diameter pipes exposed to chlorine dioxide as disinfectant. Vibien et al. [22] conducted research on the influence of chlorine and chloramine on PEX pipes, demonstrating that even with a low concentration, chlorination influenced water pipe durability.

The available literature mentions few publications on interactions between chlorine compounds and polyvinyl chloride (PVC) pipes. Most of the conducted research concerns determining long-term pipe strength in various temperatures [23]. The scope of research appears to be focused on the analysis of the usage of chlorine in water distribution systems in PVC pipes, compared with other materials, is much more common in literature [24]. There is a number of ageing methods for assessing chlorine resistance, such as ASTM Standards [25-27] or NSF Protocol for Chlorine Resistance of Plastic Piping Materials [28]. The aforementioned allows a relative assessment of a material's resistance to chlorine. Despite the fact that they fail to reflect actual operating conditions, they allow for a comparative analysis of pipes subjected to various disinfectants in variable temperature of the solutions.

\section{Materials and methodology}

This paper describes tests with the use of the ageing solutions prepared according to literature data on specific chlorine concentration, $\mathrm{pH}$ and $\mathrm{CaCO}_{3}$ contents. Dumbbell specimens were cut out from pipes and immersed in ageing solutions and stored in various temperatures. Pipe samples obtained directly from a local supply company had an outside diameter of $110 \mathrm{~mm}$ with a wall thickness of $4 \mathrm{~mm}$. HDPE pipes were manufactured on a W 60TK extruder and PVC pipes on a $2 \mathrm{~T}-14 / 8 \mathrm{M}$ twin screw extruder. The properties of polyethylene, provided by the manufacturer, were as follows: density $946 \mathrm{~kg} / \mathrm{m}^{3}, \mathrm{MFI}_{(190.5)}=0.65 \mathrm{~g} / 10 \mathrm{~min}$, volatiles $0.2 \%$, impact strength (Charpy index) $14.5 \mathrm{~mJ} / \mathrm{mm}^{2}$. Polyvinyl chloride was characterised by the following properties: K-value $=66.5$ (ISO 1628-2:2000), reduced viscosity $110.6 \mathrm{~mL} / \mathrm{g}$, bulk density $0.557 \mathrm{~g} / \mathrm{mL}$, additional components: thermal stabilizer (Stabilox EP-1039-15 from Reagens) 2\%, ground powdered chalk $9 \%$, calcium stearate $0.4 \%$, titanium white $0.1 \%$.

The tested dumbbell specimens were cut out from the HDPE and PVC pipes in an axial direction (down the length of the pipe) in accordance with ISO 527-1: 2012. The specimens for tensile tests were of the following dimensions: crosssection dimensions in the middle $4 \mathrm{~mm} \times 10 \mathrm{~mm}$, the sample's length being 
$150 \mathrm{~mm}$. Prior to the tests, all the samples were subjected to ageing in the Environmental Analysis Laboratory at Lublin University of Technology in ageing solutions with an elevated chlorine content, prepared especially for the tests. Strength, structure and chemical stability tests were conducted on samples following different ageing solution immersion periods at an Accredited Central Mining Institute Laboratory in Katowice.

\subsection{Ageing solution preparation}

The literature does not set unified standards for conducting tests in an ageing solution with the use of chlorine. Published test results are acquired for different disinfectant concentrations and different physical-chemical parameters of water, and therefore, their comparison is irrelevant. Whelton and Dietrich [14] developed a classification of solutions based on their potential practical application. Our tests were conducted on solutions with a chlorine concentration at $500 \mathrm{ppm}$ as free available $\mathrm{Cl}_{2}$ and controlled $\mathrm{pH}$ reaction. The solutions were prepared with deionised water from Nanopure Hydrolab HLP5 with 6.5\% sodium hypochlorite and calcium carbonate. The free available chlorine concentration was determined according to the ISO 7393-3: 2011 standard, the solution reaction was regulated with $\mathrm{NaOH}$ and $\mathrm{HCl}$ and maintained at $6.5 \mathrm{pH}$ according to the PN-90/G-04540.01 standard. The $\mathrm{pH}$ was controlled with a CPC-501 pH meter (Elmetron Company). Apart from controlling the $\mathrm{pH}$ reaction of water, the tests involved adding to certain solutions (in accordance with ISO 9963-1: 2001) calcium carbonate, a standard component of water used in water distribution systems. Some researchers maintain that the presence of $\mathrm{CaCO}_{3}$ in water is crucial for naturalising free radicals present in chlorinated water, and therefore for preventing polyethylene oxidation [29]. Ageing solutions and samples were stored for 672 hours (28 days) in ambient temperature $23 \pm 2^{\circ} \mathrm{C}$ and in $70^{\circ} \mathrm{C}$. Ageing solutions were characterised by the following parameters:

- the first solution was prepared with $500 \mathrm{ppm}$ chlorine concentration as free available $\mathrm{Cl}_{2}$ with no addition of $\mathrm{CaCO}_{3}$ (henceforth referred to as solution I),

- the second solution was prepared with $500 \mathrm{ppm}$ chlorine concentration as free available $\mathrm{Cl}_{2}$, with the addition of $50 \mathrm{ppm}$ of $\mathrm{CaCO}_{3}$ (henceforth referred to as solution II). In both cases, ageing solutions were prepared from scratch following each removal of samples for tests. The dumbbell specimens, prior to being placed in the ageing solutions, were rinsed three times in distilled water and dried in a desiccator for 48 hours. Subsequently, HDPE samples were immersed in solutions I and II, prepared according to the previously described procedure and placed in 4 capped glass containers. Two of the containers with solution I, however, one remained in ambient temperature $\left(23 \pm 2^{\circ} \mathrm{C}\right)$ in a dark room, and the other was placed in a laboratory drying oven KC-65 (Premed Company) at a constant temperature of $70^{\circ} \mathrm{C}$. PVC samples (Fig. 1) were placed in 4 different ageing solutions analogically to the polyethylene samples. Summing up, the samples were placed in 8 glass containers - four in ambient temperature in a dark room, and the remaining four in temperature chamber in $70^{\circ} \mathrm{C}$. 
After 168 hours (7 days) of immersion in ageing solutions, 3 samples were removed from each container, rinsed in distilled water and placed in a desiccator. After 336 hours (14 days), the next 3 samples were removed from each solution and placed in a desiccator. After 672 hours (28 days), the remaining samples were removed from the solutions and placed in a desiccator for 1 week. After each removal of the samples, new solutions were prepared. Prior to immersing in ageing solutions and after their removal during the experiment the samples were weighed, each time using AC 210S balance (Santorius Mechatronics Company).

\subsection{Mechanical properties: strength tests}

The tests were conducted in accordance with ISO 527-1:2012 standard on a Class 1 Instron 4465 tensile testing machine. Air conditioning and all specimen samples for testing were conducted in standardized conditions, namely $23 \pm 2{ }^{\circ} \mathrm{C}$, relative

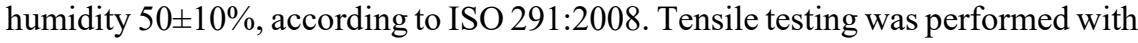
a tensile speed equal to $50 \mathrm{~mm} / \mathrm{min}$. The determination of the tensile modulus (Young's modulus) was conducted at a $1 \mathrm{~mm} / \mathrm{min}$ tensile rate.

\subsection{Chemical structure analysis}

The analysis was conducted with the use of infrared spectrometry, with a Nicolet 380 spectrometer coupled with an IR Centaurus microscope. The samples were cut out parallel and perpendicular to the surface of the tensile test dumbbell specimens (cut depth up to $1 \mathrm{~mm}$ ). The cut parallel to the specimens was performed with the aim of analysing the external surface of the material in direct contact with chlorinated water. The tests consisted of measurements of spectra in the infrared (IR) region conducted using an IR Thermo Nicolet 380 spectrometer in accordance with the ATR mode with a ZnSe crystal at $2 \mathrm{~cm}^{-1}$ resolution in the range of $500 \mathrm{~cm}^{-1}$ to $4000 \mathrm{~cm}^{-1}$. A spectral comparison of test samples with the classification reference model was conducted based on: HR Hummel Polymer Additives, HR Polymer Additives and Plasticizers, HR Aldrich Polymers, Hummel Polymer Sample Library. After noise reduction and baseline adoption, spectral comparison of the tested samples was performed.

\section{Results and discussion}

\subsection{Strength tests}

The relation between tensile strength, elongation at break, Young's modulus and the immersion period in ageing solutions as well as the composition of the solutions are presented in Table 1.

Polyethylene samples' tensile strength values do not demonstrate unambiguous tendencies. The values varied from 22.56 MPa to 21.29 MPa. After 336 hours, samples immersed in solutions at $70^{\circ} \mathrm{C}$ presented the lowest strength, while samples in solutions at ambient temperature demonstrated a slight increase in strength $(22.93 \mathrm{MPa})$. While the presence of calcium carbonate is of insignificant influence on strength values, it is the sample storage temperature which appears to 
Table 1: Tensile strength, elongation at break and Young's modulus of polyethylene samples after different periods of immersion in ageing solutions (with standard estimation).

\begin{tabular}{|c|c|c|c|c|c|c|c|c|}
\hline \multirow{2}{*}{$\begin{array}{c}\text { Immersion } \\
\text { time } \\
\text { hours }\end{array}$} & \multicolumn{8}{|c|}{ Ageing solution, $\mathrm{pH}=6.5$} \\
\hline & \multicolumn{2}{|c|}{$\begin{array}{c}\text { with } \mathrm{CaCO}_{3} \\
\left(70^{\circ} \mathrm{C}\right)\end{array}$} & \multicolumn{2}{|c|}{$\begin{array}{c}\text { without } \mathrm{CaCO}_{3} \\
\left(70^{\circ} \mathrm{C}\right)\end{array}$} & \multicolumn{2}{|c|}{$\begin{array}{c}\text { with } \mathrm{CaCO}_{3} \\
\left(23^{\circ} \mathrm{C}\right)\end{array}$} & \multicolumn{2}{|c|}{$\begin{array}{c}\text { without } \mathrm{CaCO}_{3} \\
\left(23^{\circ} \mathrm{C}\right)\end{array}$} \\
\hline \multicolumn{9}{|c|}{ Tensile strength } \\
\hline & $\mathrm{MPa}$ & SD & $\mathrm{MPa}$ & SD & $\mathrm{MPa}$ & SD & $\mathrm{MPa}$ & SD \\
\hline 0 & 22.56 & - & 22.56 & - & 22.56 & - & 22.56 & - \\
\hline 168 & 21.50 & -0.06 & 21.69 & 0.08 & 22.18 & 0.08 & 22.51 & 0.09 \\
\hline 336 & 21.97 & 0.08 & 22.67 & -0.06 & 21.89 & -0.06 & 22.47 & 0.08 \\
\hline 672 & 21.29 & 0.08 & 21.41 & -0.06 & 22.14 & 0.08 & 22.93 & -0.09 \\
\hline \multicolumn{9}{|c|}{ Elongation at break } \\
\hline & $\%$ & SD & $\%$ & SD & $\%$ & SD & $\%$ & SD \\
\hline 0 & 48.57 & - & 48.57 & - & 48.57 & - & 48.57 & - \\
\hline 168 & 60.76 & 0.38 & 55.44 & -0.29 & 41.20 & -0.33 & 39.33 & -0.30 \\
\hline 336 & 48.00 & 0.32 & 46.26 & 0,29 & 39.85 & 0.24 & 40.95 & 0.23 \\
\hline 672 & 40.69 & -0.30 & 37.16 & 0.20 & 36.60 & -0.19 & 34.66 & 0.27 \\
\hline \multicolumn{9}{|c|}{ Young's modulus } \\
\hline & $\mathrm{MPa}$ & SD & $\mathrm{MPa}$ & SD & $\mathrm{MPa}$ & SD & $\mathrm{MPa}$ & SD \\
\hline 0 & 780.55 & - & 780.55 & - & 780.55 & - & 780.55 & - \\
\hline 168 & 774.13 & 3.09 & 747.58 & -2.99 & 745.74 & 3.34 & 708.01 & -2.83 \\
\hline 336 & 625.11 & -2.50 & 544.10 & 2.17 & 527.18 & 2.98 & 503.20 & 2.01 \\
\hline 672 & 350.40 & 1.40 & 307.49 & 1.59 & 320.30 & -1.90 & 271.30 & 1.08 \\
\hline
\end{tabular}

SD - standard deviation

be of higher influence. The relations between elongation at break and time demonstrate similar tendencies in both elevated and at room temperature. These values oscillate between $48.57 \%$ and $34.66 \%$, and the lowest was obtained for samples immersed in solutions and subsequently placed in the atmospheric air for 672 hours. For samples immersed in solutions stored at $70^{\circ} \mathrm{C}$, elongation slightly increased in the first 168 hours, which was, however, followed by a similar decrease as in the case of samples placed in solutions at ambient temperature. Young's modulus values ranged from $780.55 \mathrm{MPa}$ to $271.30 \mathrm{MPa}$. The lowest value was recorded for a sample immersed in ambient temperature solution without $\mathrm{CaCO}_{3}$. Nevertheless, a similar falling tendency of this indicator's value was observed for all samples.

Slightly different tendencies can be observed in the case of PVC samples. Throughout the experiment, tensile strength values increased slightly with the immersion time of samples in ageing solutions (Table 2). While the increase is more observable for samples immersed in solutions and stored at $70^{\circ} \mathrm{C}$ (from $48.95 \mathrm{MPa}$ to $54.62 \mathrm{MPa}$ ), it is hardly noticeable when considering samples in solutions at ambient temperature. Elongation at break slightly declines with time for all the samples. The most significant decrease was observed for samples at an elevated temperature, where the values changed from $51.16 \%$ to $18.85 \%$ after 336 hours and $21.04 \%$ after 672 hours. The lowest values were noted for solutions 
Table 2: Tensile strength, elongation at break and Young's modulus of polyvinyl chloride samples after different ageing solutions' immersion time (with a standard estimation).

\begin{tabular}{|c|c|c|c|c|c|c|c|c|}
\hline \multirow{2}{*}{$\begin{array}{c}\text { Immersion } \\
\text { time } \\
\text { hours }\end{array}$} & \multicolumn{8}{|c|}{ Ageing solution, $\mathrm{pH}=6.5$} \\
\hline & \multicolumn{2}{|c|}{$\begin{array}{l}\text { with } \mathrm{CaCO}_{3} \\
\quad\left(70^{\circ} \mathrm{C}\right)\end{array}$} & \multicolumn{2}{|c|}{$\begin{array}{c}\text { without } \mathrm{CaCO}_{3} \\
\left(70^{\circ} \mathrm{C}\right)\end{array}$} & \multicolumn{2}{|c|}{$\begin{array}{c}\text { with } \mathrm{CaCO}_{3} \\
\left(23^{\circ} \mathrm{C}\right)\end{array}$} & \multicolumn{2}{|c|}{$\begin{array}{c}\text { without } \mathrm{CaCO}_{3} \\
\left(23^{\circ} \mathrm{C}\right)\end{array}$} \\
\hline \multicolumn{9}{|c|}{ Tensile strength } \\
\hline & $\mathrm{MPa}$ & SD & $\mathrm{MPa}$ & SD & $\mathrm{MPa}$ & SD & $\mathrm{MPa}$ & SD \\
\hline 0 & 48.95 & - & 48.95 & - & 48.95 & - & 48.95 & - \\
\hline 168 & 53.15 & 0.15 & 53.60 & -0.21 & 50.29 & 0.20 & 50.51 & 0.21 \\
\hline 336 & 54.62 & -0.21 & 54.02 & 0.16 & 49.40 & -0.14 & 48.99 & -0.19 \\
\hline 672 & 53.83 & 0.21 & 53.80 & -0.19 & 49.59 & 0.19 & 49.41 & 0.19 \\
\hline \multicolumn{9}{|c|}{ Elongation at break } \\
\hline & $\%$ & SD & $\%$ & SD & $\%$ & SD & $\%$ & SD \\
\hline 0 & 51.16 & - & 51.16 & - & 51.16 & - & 51.16 & - \\
\hline 168 & 27.04 & 0.28 & 23.39 & -0.1 & 50.71 & 0.21 & 48.00 & 0.17 \\
\hline 336 & 22.75 & -0.30 & 18.85 & 0,29 & 41.48 & 0.18 & 36.20 & 0.21 \\
\hline 672 & 26.60 & 0.10 & 21.04 & 0.19 & 38.77 & 0.19 & 37.25 & -0.17 \\
\hline \multicolumn{9}{|c|}{ Young's modulus } \\
\hline & $\mathrm{MPa}$ & SD & $\mathrm{MPa}$ & SD & $\mathrm{MPa}$ & SD & $\mathrm{MPa}$ & SD \\
\hline 0 & 2645.70 & - & 2645.70 & - & 2645.70 & - & 2645.70 & - \\
\hline 168 & 3554.00 & 14.21 & 3201.46 & 12.80 & 3348.00 & 13.39 & 3264.00 & 14,06 \\
\hline 336 & 3115.00 & 12.46 & 2762.99 & 11.05 & 2786.00 & 11.14 & 2706.00 & 10.82 \\
\hline 672 & 3210.66 & 12.80 & 2742.05 & 11.59 & 2897.51 & 10.90 & 2827.00 & 11.30 \\
\hline
\end{tabular}

SD - standard deviation.

without $\mathrm{CaCO}_{3}$. Young's modulus ranged from $2645.7 \mathrm{MPa}$ to 3554.00 after 168 hours and up to $3210.66 \mathrm{MPa}$ after 672 hours. These values were observed for samples in solutions with $\mathrm{CaCO}_{3}$ at $70^{\circ} \mathrm{C}$.

Based on the obtained results, it is difficult to explicitly determine the influence that solutions have on mechanical properties at particular stages of contact between the material and the solution. Temporary strengthening of some samples might have resulted from structural changes in the sample material, such as increased crystallinity or substitution of hydrogen atoms with chlorine atoms (PVC samples). Nevertheless, structure analysis confirmed material degradation, which may result in migration of antioxidants or other low-molecular compounds into the water being in contact with the pipe.

\subsection{Chemical structure analysis}

IR spectroscopy tests were conducted in order to analyse the chemical structure of the material and facilitate the assessment of material degradation degree caused by the immersion of the samples in ageing solutions. IR spectroscopy consists of analysing the absorption of specific wavelength infrared radiation, which allows the analysis of oxidation products and polymer degradation. As a consequence, oxidation of polymer chains leads to their shortening and thus material weakening. IR tests showed greater changes in PVC structure when compared with HDPE. 
PVC samples from solutions with and without $\mathrm{CaCO}_{3}$ at $70^{\circ} \mathrm{C}$ exhibited distinct differences in spectrum between the exterior and interior polymer layer. Degradation concerns mainly the exterior layer and the changes in polymer chain are to a considerable extent conformational (Figs 1 and 2). The peak is found at $1740 \mathrm{~cm}^{-1}$ (the stretching vibration of $\mathrm{C}=\mathrm{O}$ group), $1620 \mathrm{~cm}^{-1}$ (stretching $\mathrm{C}=\mathrm{C}$ ), $\sim 800 \mathrm{~cm}^{-1}$ (symmetrical and asymmetrical stretching vibration $\mathrm{C}-\mathrm{Cl}$ ). These peaks suggest the occurrence of the polymer degradation process and the emergence of new bonds as a result of oxidation.

Significant changes are also detected in regions $1200-1270 \mathrm{~cm}^{-1}$ and 600 $880 \mathrm{~cm}^{-1}$. At an approximately $1240 \mathrm{~cm}^{-1}$ frequency peak, splitting can be observed (bending vibration of $\mathrm{CH}-\mathrm{CCl}$ group) into two around $1200 \mathrm{~cm}^{-1}$ (asymmetrical bending vibration of $\mathrm{CH}-\mathrm{Cl}$ group) and $1268 \mathrm{~cm}^{-1}$ (symmetrical bending vibration of $\mathrm{CH}-\mathrm{Cl}$ group). These peaks are more intensive in the case of the exterior layer. It may be concluded that substitution of hydrogen atoms with chlorine atoms could have taken place. The decrease of peak intensity, characteristic of the deformation vibration of the $\mathrm{CH}_{2}$ group within $1300-1450 \mathrm{~cm}^{-1}$ confirms the occurrence of this phenomenon. An intensity decrease of $1420 \mathrm{~cm}^{-1}, 1320 \mathrm{~cm}^{-1}$ and $1090 \mathrm{~cm}^{-1}$ peaks may also indicate chain degradation (disintegration into smaller units - mers - or branch formation). In the lower frequency region $\left(600-900 \mathrm{~cm}^{-1}\right)$, in the case of the interior layer, a sharp narrow peak is detected at $875 \mathrm{~cm}^{-1}$, which may be a result of chlorine vibration $(\mathrm{CCl})$. In the case of the exterior layer, the peak is shifted to lower frequencies and split into two peaks $\left(840 \mathrm{~cm}^{-1}-\right.$ symmetrical stretching vibration $\mathrm{C}-\mathrm{Cl}, \sim 790 \mathrm{~cm}^{-1}$ - asymmetrical stretching vibration-Cl).

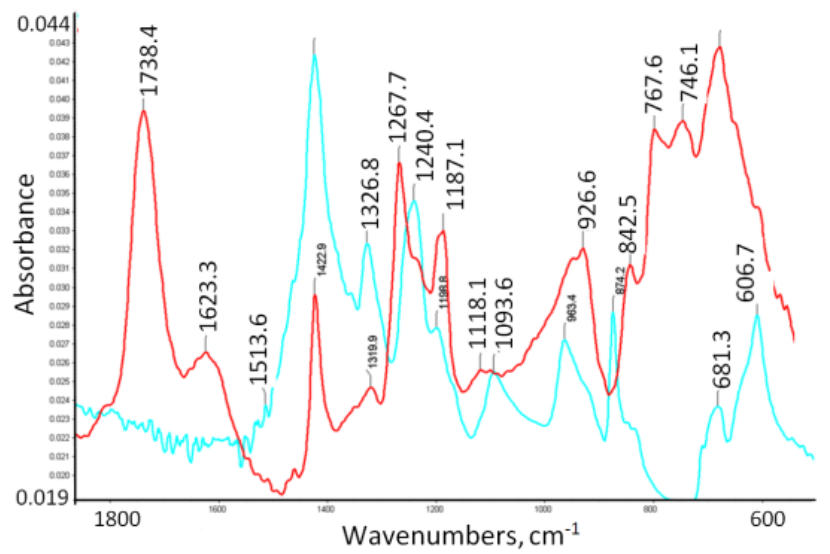

Figure 1: PVC sample IR spectrum after 672 hours' immersion period in solution with $\mathrm{CaCO}_{3}$ at $23^{\circ} \mathrm{C}$. Exterior (red) and interior (blue) layers' comparison; spectrum range $500-1800 \mathrm{~cm}^{-1}$. 


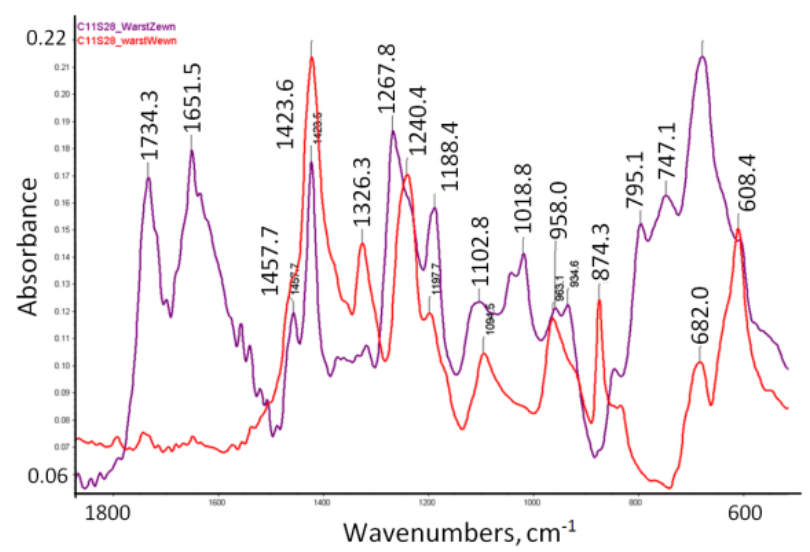

Figure 2: PVC sample IR spectrum after 672 hours' immersion period in solution with $\mathrm{CaCO}_{3}$ at $70^{\circ} \mathrm{C}$. Exterior (violet) and interior (red) layers' comparison; spectrum range $500-1800 \mathrm{~cm}^{-1}$.

In addition, the analysis included tests of exterior and interior layer of polyethylene samples, where a certain discrepancy between the spectra of both layers can be observed as well (Fig. 3). A distinct peak, characteristic of the stretching vibration of the $\mathrm{C}=\mathrm{O}$ group at $1740 \mathrm{~cm}^{-1}$, can be detected in the exterior layer. These changes may indicate polyethylene chain degradation, branch formation or formation of oxidation reaction products. However, the changes are relatively insignificant when compared with changes in PVC. The analysis of the relation between the intensity of $2900 \mathrm{~cm}^{-1}$ peak, characteristic of polymer (symmetrical stretching vibration of $\mathrm{CH}_{2}$ group), and $1750 \mathrm{~cm}^{-1}$ peak, characteristic of the oxidation process products (stretching vibration $\mathrm{C}=\mathrm{O}$ ), may lead to the conclusion that the degradation and oxidation process was completed at approximately $11 \%$. Fig. 3 shows a minor peak around $1600 \mathrm{~cm}^{-1}$. Gedde and Ifwarson [5] having conducted cross-linked polyethylene pipe tests suggested that bonds detected between $1680 \mathrm{~cm}^{-1}$ and $1500 \mathrm{~cm}^{-1}$ are linked with water sorption through oxidized material. A slight weight gain of polyethylene samples after removal from ageing solutions may prove water penetration into the material. For instance, the biggest weight gain of HDPE samples was registered after 672 hours of immersion in ageing solution at $70^{\circ} \mathrm{C}$ from $10.30 \mathrm{~g}$ to $10.63 \mathrm{~g}$. In the case of PVC samples, the situation was the reverse, the weight decreased in the majority of cases. The difference was similarly the most significant at $70^{\circ} \mathrm{C}$, in which conditions the weight of the sample dropped from $14.60 \mathrm{~g}$ to $14.46 \mathrm{~g}$ after 672 hours in ageing solution. 


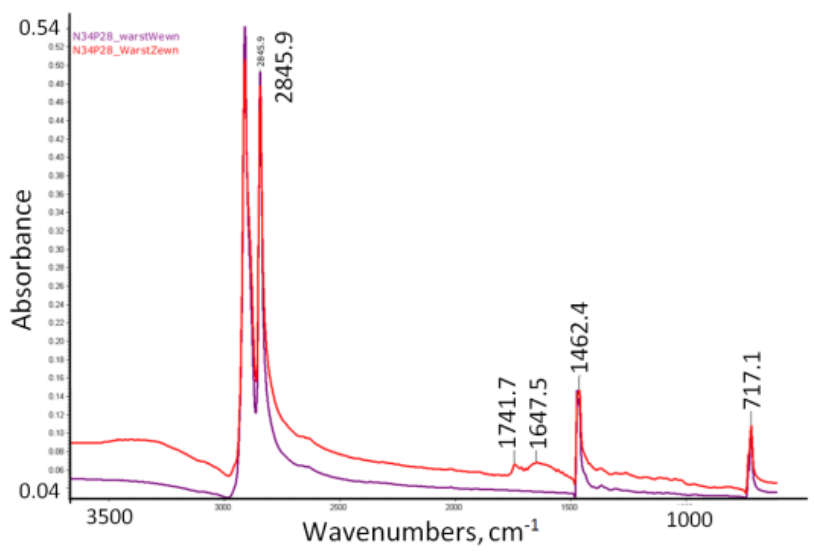

Figure 3: IR spectrum of exterior (red) and interior (violet) layer of the polyethylene sample after 672 hours' immersion period in solution without $\mathrm{CaCO}_{3}$ at $23^{\circ} \mathrm{C}$.

\section{Conclusions}

The research results of mechanical properties of pipes treated with chlorinated water showed that static tensile tests have not indicated significant changes of HDPE or PVC samples. The observed temporary consolidation of certain samples could have resulted from structural changes of the material, e.g. increased crystallinity or chloride atom substitutions of hydrogen atoms (in PVC samples).

Infrared spectrometry chemical structure analysis evidenced changes in the test samples, which indicated material degradation caused by chlorinated water. Chemical changes concern predominantly the exterior layer of the material and are more distinct in PVC samples than HDPE samples.

Upon removal of HDPE samples from the solutions, their weight slightly increased, which appears to indicate water penetration into the pipes. A slight decrease of samples' weight was noted in the case of PVC samples.

The results of the short-term analysis of samples with increased chlorine content do not, however, provide unambiguous information on HDPE and PVC pipes' strength. No significant strength deterioration was noted; however, the structure analyses indicate material degradation onset. Consequently, tests conducted over an extended period of time and in conditions to a greater extent resembling genuine water pipe network operating conditions should prove more reliable. Due to material degradation, which may result in migration of antioxidants or other low-molecular compounds into the water being in contact with the pipe, migration tests should also be performed.

\section{Acknowledgement}

This paper was financed by statutory activity of the Faculty of Environmental Engineering, Lublin University of Technology. 


\section{References}

[1] Świderska-Bróż, M., Wolska, M., Causes Underlying Free Chlorine Decay in the Water Distribution System. Ochrona Środowiska, 29 (3) pp. 19-24, 2007.

[2] Gedde, U.W., Viebke J., Leijstronm, J.H., Ifwarson M., Long-term properties of hot-water polyolefin pipes - a review, Polymer Engineering and Science, 34, pp. 1773-1787, 1994.

[3] Zebger, I., Goikoetxea, A.B., Jensen, S., Ogilby, P.R., Degradation of vinyl polymer films upon exposure to chlorinated water: the pronounced effect of a sample's thermal history, Polymer Degradation and Stability, 80, pp. 293 304, 2003.

[4] Polish Regulation of the Minister of Health on the quality of water intended for human consumption (2007).

[5] Gedde, U.W., Ifwarson, M., Molecular structure and morphology of crosslinked polyethylene in an aged hot-water pipe, Polymer Engineering and Science, 30, pp. 202-210, 1990.

[6] Viebke, J., Gedde, W., Antioxidant diffusion in polyethylene hot-water pipes, Polymer Engineering and Science, 37, pp. 896-911, 1997.

[7] Smith, G.D., Karlsson, K., Gedde, U.W., Modeling of Antioxidant Loss from Polyolefins in Hot-Water Applications. 1. Model and Application to Medium Density Polyethylene Pipes, Polymer Engineering and Science, 32(10), pp. 658-667, 1992.

[8] Lehtola, M.J., Miettinen, I.T., Lampola, T., Hirvonen, A., Vartiainen, T., Martikainen, P.J., Pipeline materials modify the effectiveness of disinfectants in drinking water distribution systems, Water Research, 39, pp.1962-1971, 2005.

[9] Castillo Montes, J., Cadoux, D., Creus, J., Touzain, S., Gaudichet-Maurin, E., Correc, O. Ageing of polyethylene at raised temperature in contact with chlorinated sanitary hot water. Part I - Chemical aspects: Polymer Degradation and Stability, 97, pp. 149-157, 2012.

[10] Mitroka, S.M., Smiley, T.D., Tanko, J.M., Dietrich A.M., Reaction mechanism for oxidation and degradation of high density polyethylene in chlorinated water, Polymer Degradation and Stability, 98, pp. 1369-1377, 2013.

[11] Dear, J.P., Mason, N.S., The effects of chlorine depletion of antioxidants in polyethylene. Polymers and Polymer Composites 9, pp. 1-13, 2001.

[12] J. Hassinen, M. Lundbäck, M. Ifwarson, U.W. Gedde, Deterioration of polyethylene pipes exposed to chlorinated water, Polymer Degradation and Stability, 84, pp. 261-267, 2004.

[13] Andersson, U., Ifwarson, M., In Proceeding of Plastic Pipes XI, Munich, Germany (2001).

[14] Whelton, A.J., Dietrich, A.M., Critical considerations for the accelerated ageing of high-density polyethylene potable water materials, Polymer Degradation and Stability, 94, pp. 1163-1175, 2009. 
[15] Castagnetti, D., Scirè Mammano, G., Dragoni, E., Effect of chlorinated water on the oxidative resistance and the mechanical strength of polyethylene pipes, Polymer Testing, 30, pp. 277-285, 2011.

[16] Colin, X., Audouin, L., Verdu, J., Rozental-Evesque, M., Rabaud, B., Martin, F., Bourgine, F., Aging of polyethylene pipes transporting drinking water disinfected by chlorine dioxide. I. Chemical aspects, Polymer Engineering and Science, 49, pp.1429-1437, 2009.

[17] Colin, X., Audouin, L., Verdu, J., Rozental-Evesque, M., Rabaud, B., Martin, F., Bourgine, F., Aging of polyethylene pipes transporting drinking water disinfected by chlorine dioxide. Part II-Lifetime prediction, Polymer Engineering and Science, 49, pp. 1642-1652, 2009.

[18] Yu, W., Azhdar, B., Andersson, D., Reitberger, T., Hassinen, J., Hjertberg, T., Gedde, U.W., Deterioration of polyethylene pipes exposed to water containing chlorine dioxide, Polymer Degradation and Stability, 96, pp. 790-797, 2011.

[19] Oertli, A.G., Ifwarson, M., In Proceedings of Plastic Pipes XI, Munich, Germany, 2001.

[20] Devilliers, C., Fayolle, B., Laiarinandrasana, L., Oberti, S., GaudichetMaurin, E., Kinetics of chlorine-induced polyethylene degradation in water pipes, Polymer Degradation and Stability, 96, pp. 1361-1368, 2011.

[21] Gill, S., Knapp, R.J., Bradley, S.W., Bradley, W.L., In Proceeding of Plastic Pipes X, Goteborg, Sweden, 28, p. 309, 1999.

[22] Vibien, P., Couch, J., Oliphant, K., Zhou, W., Zhang, B., Chudnovsky, A., In Proceedings of Plastic Pipes XI, Munich, Germany, 2001.

[23] Janson, L.E., Plastics Pipes for Water Supply and Sewage Disposal, 4th edition, Borealis, Majornas CopyPrint AB, Stockholm, 2003.

[24] Heim, T.H, Dietrich, A.M., Sensory aspects and water quality impacts of chlorinated and chloraminated drinking water in contact with HDPE and cPVC pipe, Water Research, 41, pp. 757-764, 2007.

[25] ASTM F2023 Standard Test Method for Evaluating the Oxidative Resistance of Crosslinked Polyethylene (PEX) Tubing and Systems to Hot Chlorinated Water, ASTM International, USA (2005).

[26] ASTM F2023 Standard Test Method for Evaluating the Oxidative Resistance of Polyethylene (PE) Pipe to Chlorinated Water. ASTM International, USA (2007).

[27] ASTM D6284 Standard Test Method for Rubber Property - Effect of Aqueous Solutions with Available Chlorine and Chloramines. ASTM International (2005).

[28] NSF Protocol for Chlorine Resistance of Plastic Piping Materials, USA, 1999.

[29] H. Utsumi, M. Hakoda, S. Shimbara, H. Nagaoka, Y.S. Chung, A. Hamada, Active oxygen species generated during chlorination and ozonation, Water Science and Technology, 30, pp. 91-99, 1994. 